\title{
The quest for effective pain control during suture adjustment after strabismus surgery: a study evaluating supplementation of $2 \%$ lidocaine with $0.4 \%$ ropivacaine
}

\author{
This article was published in the following Dove Press journal: \\ Journal of Pain Research \\ 14 January 2015 \\ Number of times this article has been viewed
}

\author{
Howard D Palte \\ Kara M Cavuoto \\ Lalitha Sundararaman \\ Steven Gayer \\ Joyce Schiffman \\ Hilda Capo
}

Bascom Palmer Eye Institute, Miami, FL, USA

\begin{abstract}
Purpose: To determine whether the addition of $0.4 \%$ ropivacaine to the standard $2 \%$ lidocaine peribulbar anesthetic block improves pain scores during suture adjustment in patients undergoing strabismus surgery with adjustable sutures.

Methods: Prospective, double-blind study of 30 adult patients aged 21-84 years scheduled for elective strabismus surgery with adjustable sutures. Patients were divided into two groups of 15 patients each based on the local anesthetic. Group A received 2\% lidocaine and Group B received $2 \%$ lidocaine $/ 0.4 \%$ ropivacaine. Pain was assessed using the visual analog scale (VAS) preoperatively and at 2, 4, and 6 hours postoperatively. The Lancaster red-green test was used to measure ocular motility at the same time points.

Results: The pain scores in the two groups were low and similar at all measurement intervals. The VAS for Group A versus Group B at 2 hours $(1.7$ versus $2.4, P=0.5)$ and 4 hours ( 3.5 versus $3.7, P=0.8$ ) showed no benefit from the addition of ropivacaine. At 6 hours, the VAS (3.7 versus 2.7 ) was not statistically significant, but the $95 \%$ confidence interval indicated that ropivacaine may provide some benefit. A repeated measures ANOVA did not find a statistically significant difference in VAS scores over time $(P=0.9)$. In addition, the duration of akinesia was comparable in both groups $(P=0.7)$.
\end{abstract}

Conclusion: We conclude that the 50:50 mixture of 2\% lidocaine with $0.4 \%$ ropivacaine as compared to $2 \%$ lidocaine in peribulbar anesthetic blocks in adjustable-suture strabismus surgery does not produce significant improvements in pain control during the postoperative and adjustment phases. In addition, ropivacaine did not impair return of full ocular motility at 6 hours, which is advantageous in adjustable-suture strabismus surgery.

Keywords: adjustable-suture strabismus surgery, postoperative ocular motility, local anesthetic block, postoperative pain

\section{Introduction}

The goal of strabismus surgery is to align the eyes, reduce diplopia, and restore binocular vision. This is accomplished by either a fixed- or adjustable-suture surgical technique. Adjustable-suture surgery is a two-stage procedure for correction of strabismus. ${ }^{1,2}$ In this technique, the extraocular muscle is secured during surgery with a temporary or sliding knot. When the patient is fully awake and ocular motility has fully returned, the alignment is fine-tuned by repositioning the adjustable knot before it is permanently tied. Studies indicate that this procedure may reduce the necessity for repeat interventions by $50 \%$. 3,4
Correspondence: Kara Cavuoto Bascom Palmer Eye Institute, 900 NW 17th Street, Miami, FL 33|36, USA

Tel +l 3053266324

Fax +l 3055473675

Email kcavuoto@med.miami.edu 
At Bascom Palmer Eye Institute, the majority of adjustablesuture strabismus surgeries on adults are performed under regional ophthalmic anesthesia. The attending anesthesiologist administers an inferotemporal extraconal (peribulbar) block using 4-6 mL of $2 \%$ lidocaine. Traditionally, lidocaine is the anesthetic of choice because it has been shown to have minimal residual motor effect at 6 hours. $^{5}$ After surgery, the patient returns to the ward and receives supplemental analgesia as needed. Approximately 6 hours later, the final adjustments are performed under topical anesthesia with proparacaine drops. This adjustment stage is often associated with pain and patient movement. The management of this pain is difficult because administration of supplemental analgesia may produce sedation, render the patient uncooperative, obstruct motility measurements, decrease the accuracy of adjustment, and delay discharge. In addressing this problem, we postulated that the addition of ropivacaine to the standard local anesthetic (LA) solution would improve outcomes because of a longer duration of action and greater selectivity for A-delta and C (pain) nerve fibers. ${ }^{6}$ The primary aims of this study were to determine whether the addition of $0.4 \%$ ropivacaine to the standard LA ( $2 \%$ lidocaine): 1$)$ improved pain scores during suture adjustment, and 2) did not prolong the full return of ocular motility.

\section{Materials and methods}

This was a prospective, double-masked clinical trial conducted with approval of the University of Miami Institutional Research Board (study \#20110472; Miami, FL, USA). All adult patients scheduled for elective strabismus surgery with adjustable suture were invited to participate in the study, with the exception of those undergoing combined horizontal and vertical muscle surgery, who were excluded. Thirty patients were recruited. Informed consent was obtained from each patient the day before surgery.

On the day preceding surgery, all patients underwent an anesthesia preoperative evaluation and baseline motility assessment using Lancaster red-green testing. The test is utilized to measure horizontal, vertical, and torsional strabismus $^{7,8}$ and uses red- and green-colored linear lights that are projected onto a screen. The lasers employed are of special ophthalmic design and pose no patient risk. With the patient wearing red-green glasses, the examiner shines one light on the screen and the patient superimposes a handheld light over it. The distance between the lights is measured and recorded. We documented eye movements in a plane perpendicular to the proposed strabismus surgery in order to ensure motility was not affected by surgery or edema. For example, if a patient underwent surgery for horizontal strabismus, the motility was recorded in vertical gazes.

On the day of surgery, patients were reevaluated in the operating room holding area using standard American Society of Anesthesiology (ASA) monitors. Intravenous sedation with $2 \mathrm{mg}$ of midazolam and $50 \mu \mathrm{g}$ of fentanyl was administered. The hospital pharmacist prepared the LA solutions and assigned the anesthesia treatment so that one-half received 2\% lidocaine (APP Pharmaceuticals LLC, Schaumburg, IL, USA) (Group A) and one-half received a 50:50 mixture with an end concentration of $2 \%$ lidocaine $/ 0.4 \%$ ropivacaine (Naropin ${ }^{\circledR}$; AAP Pharmaceuticals LLC) (Group B). Ropivacaine, a pure S-enantiomer of propivacaine, is a longacting amide LA agent that produces reversible inhibition of nerve conduction via inhibition of sodium ion influx. It penetrates large myelinated motor fibers weakly because of its low lipid solubility, and therefore produces limited motor block. ${ }^{9}$ We selected a concentration of $0.4 \%$ ropivacaine based on previous studies that assessed the efficacy of ropivacaine for ocular anesthesia. ${ }^{10-19}$ The patients and all health care providers were masked to the LA content. All solutions were mixed with recombinant hyaluronidase (Hylenex ${ }^{\circledR}$; Halozyme Therapeutics Inc., San Diego, CA, USA) at a concentration of $10 \mathrm{iU} / \mathrm{mL}$. Fifteen minutes before surgery, a peribulbar block using 4-6 mL of LA solution was performed by one of three attending anesthesiologists. The time was recorded as a reference point for future assessments.

In the operating room, additional sedation, including a propofol infusion $(25-50 \mu \mathrm{g} / \mathrm{kg} / \mathrm{min})$, was given as necessary. The same surgeon performed all surgeries. After surgery, patients returned to the post-anesthesia care unit. Supplemental analgesia (nonsteroidal anti-inflammatory) consisting of $30 \mathrm{mg}$ of intravenous ketorolac was administered to patients reporting moderate pain scores (between 3 and $6 \mathrm{~cm}$ on the visual analog scale [VAS]). The return of extraocular muscle function was monitored by Lancaster red-green testing conducted at 2, 4, and 6 hours post-block, and after adjustable-suture correction. Pain was assessed using the VAS at the same time points. The VAS, commonly used to assess acute pain, is defined on a $10 \mathrm{~cm}$ horizontal line, on which the patient's pain intensity is represented by a point between $0 \mathrm{~cm}$ and $10 \mathrm{~cm}$, with corresponding word descriptors of "no pain" and "worst pain imaginable". ${ }^{20}$ The degree of pain was self-reported by the patient and recorded by an anesthesiologist who was masked to the LA administered.

\section{Statistical analysis}

A $t$-test was used to compare pain scores between the two LA solutions. Categorical variables such as strabismus type were 
compared with Fisher's exact test. Repeated measures analysis of variance (ANOVA) was used to test the difference in VAS scores between the two anesthesia groups over time. A $P$-value of 0.05 or less was considered statistically significant. We planned the study to detect a 3-point difference in pain scores, assuming a standard deviation of 2.8 points. The required sample size with a type I error of 0.05 and a power of $80 \%$ was 30 (15 in each anesthesia group). Additionally, we presented VAS-derived $95 \%$ confidence intervals in order to estimate likely differences in pain scores. IBM SPSS Statistics version 22 was used for statistical analysis.

\section{Results}

Thirty patients undergoing strabismus surgery with adjustable sutures were assigned to one of two groups based on the LA administered. The demographic data of the patients, diagnosis, and surgical treatments are presented in Table 1. Twenty-six operations were performed for horizontal strabismus and four for vertical strabismus. The latter four were deemed too small a group to obtain meaningful analysis, and were excluded from motility measurements. Eighteen (60\%) procedures were reoperations (Table 1).

The mean pain scores in the two groups were relatively low. The pain scores were similar between Groups A and B at the 2-, 4-, and 6-hour and post-adjustment assessments.

Table I Baseline characteristics of adult patients undergoing strabismus surgery with adjustable sutures by anesthetic group

\begin{tabular}{|c|c|c|c|}
\hline & $\begin{array}{l}\text { Lidocaine } \\
\text { group } \\
(n=15)\end{array}$ & $\begin{array}{l}\text { Lidocaine + } \\
\text { ropivacaine } \\
\text { group } \\
(n=15)\end{array}$ & $P$-value \\
\hline \multicolumn{4}{|l|}{ Age } \\
\hline Mean \pm SD & $56 \pm 18$ & $50 \pm 19$ & $0.4 *$ \\
\hline (minimum to maximum) & $(2 \mid-84)$ & $(23-78)$ & \\
\hline \multicolumn{4}{|l|}{ Sex, n (\%) } \\
\hline Male & $3(20)$ & $4(27)$ & $1.0 * *$ \\
\hline Female & $12(80)$ & II (73) & \\
\hline \multicolumn{4}{|l|}{ Eye operated, n (\%) } \\
\hline Right & $7(47)$ & $9(60)$ & $0.7 * *$ \\
\hline Left & $8(53)$ & $6(40)$ & \\
\hline \multicolumn{4}{|l|}{ Strabismus type, n (\%) } \\
\hline Esotropia & $6(40)$ & $8(53)$ & $0.4^{* *}$ \\
\hline Exotropia & $7(47)$ & $5(33)$ & \\
\hline Left hypotropia & 0 & I (7) & \\
\hline Left hypertropia & 0 & I (7) & \\
\hline Right hypertropia & $2(13)$ & 0 & \\
\hline \multicolumn{4}{|l|}{ Surgery, n (\%) } \\
\hline First & $5(33)$ & $7(47)$ & $0.7^{* *}$ \\
\hline Reoperation & $10(67)$ & $8(53)$ & \\
\hline
\end{tabular}

Notes: *Student's t-test; **Fisher's exact test. Abbreviation: SD, standard deviation.
In addition, comparable numbers of patients reported a score of 5 or higher at 2 hours (2/15 versus 3/15), at 4 hours $(6 / 15$ versus $5 / 15)$, at 6 hours $(7 / 15$ versus $5 / 15)$, and after adjustment (1/15 versus 1/15) in Group A (lidocaine) versus Group B (lidocaine/ropivacaine). The VAS for Group A versus Group B at 2 hours ( 1.7 versus $2.4, P=0.5)$ and 4 hours ( 3.5 versus $3.7, P=0.8$ ) showed no benefit from the addition of ropivacaine. At 6 hours, the VAS (3.7 versus 2.7) was not statistically significant, but the $95 \%$ confidence interval indicated that ropivacaine may provide some benefit. Post-adjustment, the difference was 0.5 points, and the 95\% confidence interval indicates that, if there is a benefit, it is likely less than 1.8 points. A repeated measures ANOVA did not find a statistically significant difference in VAS scores over time ( $P=0.9)$. The 2-, 4-, and 6-hour post-block VAS and the post-adjustment VAS are illustrated in Table 2.

There were no large differences in VAS scores between those undergoing first operations and those undergoing reoperations. At all time points, the differences were 2 points or less.

The duration of akinesia appeared similar in both groups. Differences in motility at 6 hours post-block in elevation and depression in patients undergoing horizontal strabismus surgery were not significant as evidenced by Lancaster redgreen testing $(\mathrm{P}=0.7$ and $\mathrm{P}=0.7$, respectively $)$.

\section{Discussion}

Several studies have compared the efficacy of ropivacaine with other commonly used LA preparations and demonstrated its suitability for cataract and intraocular surgery. ${ }^{10-12}$ At concentrations of $0.5 \%-1 \%$, ropivacaine produces sensory anesthesia similar to bupivacaine $(0.5 \%-0.75 \%)$. In comparison with $2 \%$ lidocaine, it causes less ocular akinesia and prolonged sensory block (294 versus 143 minutes). ${ }^{13}$ In a double-blind, randomized study comparing ropivacaine $(0.5 \%)$, bupivacaine $(0.375 \%)$ /lidocaine $(1 \%)$, and ropivacaine $(0.5 \%) /$ lidocaine $(1 \%)$, Perello et al demonstrated that ropivacaine provided satisfactory operating conditions and less akinesia. ${ }^{14}$ This observation has relevance for adjustablesuture strabismus surgery because, in these cases, the ideal LA provides optimal sensory block and short-acting motor block. In contrast, Nociti et al compared the efficacy of ropivacaine $(1 \%)$ and bupivacaine $(0.75 \%)$ in peribulbar anesthesia, ${ }^{15}$ and demonstrated that ropivacaine produced a faster onset of sensory block but found no differences in ocular motility indices.

In a prospective, randomized, double-blinded study of 68 patients, Gioia et al assessed the efficacy of varying strengths 
Table 2 Pain outcomes in adult patients after strabismus surgery with adjustable sutures by anesthesia type

\begin{tabular}{llll}
\hline & $\begin{array}{l}\text { Lidocaine group } \\
(\mathbf{n}=\mathbf{I 5}) \\
(\mathbf{m i n i m u m} \text { to maximum) }\end{array}$ & $\begin{array}{l}\text { Lidocaine + ropivacaine group } \\
(\mathbf{n}=\mathbf{1 5}) \\
(\text { minimum to maximum) }\end{array}$ & $\begin{array}{l}\text { Difference } \\
\text { (95\% confidence interval) }\end{array}$ \\
\hline $\begin{array}{l}\text { Pre-block VAS score, } \\
\text { mean (SD) }\end{array}$ & $0(0)$ & $0(0)$ & -0.7 \\
2-hour post-block & $1.7(2.5)$ & $2.4(3.2)$ & $(-2.8$ to 1.5$)$ \\
VAS score, mean (SD) & $(0-8)$ & $(0-10)$ & -0.3 \\
4-hour post-block & $3.5(2.1)$ & $3.7(3.3)$ & $(-2.4$ to 1.8$)$ \\
VAS score, mean (SD) & $(0-7)$ & $(0-9)$ & 0.9 \\
6-hour post-block & $3.7(2.0)$ & $2.7(2.5)$ & $(-0.8$ to 2.6$)$ \\
VAS score, mean (SD) & $(0-8)$ & $(0-7)$ & 0.5 \\
Post-adjustment & $1.9(1.7)$ & $1.4(2.0)$ & $(-0.9$ to 1.8$)$ \\
VAS score, mean (SD) & $(0-5)$ & $(0-6)$ & $0.5^{* *}$ \\
\hline
\end{tabular}

Notes: $* P=0.9$, repeated measures analysis of variance; $* *$ Student's $t$-test.

Abbreviations: SD, standard deviation; VAS, visual analog scale.

of ropivacaine $(0.5 \%, 0.75 \%$, and $1 \%)$ for peribulbar anesthesia, ${ }^{16}$ and found that $0.75 \%$ and $1 \%$ ropivacaine produced "quick and deep sensory and motor block" in more than $80 \%$ of patients, but that $0.5 \%$ ropivacaine produced akinesia in fewer than $60 \%$. This finding suggests that ropivacaine concentrations as high as $0.5 \%$ may be appropriate for adjustable-suture strabismus surgery.

Kallio et al compared retrobulbar and peribulbar ropivacaine $(0.2 \%)$ with lidocaine $(1 \%)$ for transscleral or retinal photocoagulation. ${ }^{17}$ They demonstrated no differences in either the quality of analgesia or the need for supplementary blocks. Furthermore, they found that $0.2 \%$ ropivacaine produced significantly less akinesia than $1 \%$ lidocaine. Importantly, they observed that there was a correlation between persistence of eye movements and inadequate analgesia after lidocaine blocks, but that this was not the case with ropivacaine. These observations support our postulate that, at the correct concentration, ropivacaine may provide improved analgesia during suture adjustments.

In a prospective, double-blinded, adjustable-suture surgery study, Walters et al compared the efficacy of sub-Tenon's ropivacaine $(0.2 \%)$ against normal saline for postoperative analgesia. ${ }^{18}$ In this study, 20 patients received general anesthesia and an intraoperative block. The primary study outcomes were postoperative pain and ease of suture adjustment. The ropivacaine group had significantly lower postoperative pain scores $(P<0.05)$ and no difference in the ease-of-adjustment scores. Unfortunately, the time interval for return of ocular motility was not documented. The authors only commented that "at 4 hours the ropivacaine motor blockade would be expected to have worn off while maintaining a sensory block." ${ }^{18}$ In our study, we confirm that recovery of full ocular motility is achieved by 6 hours.
In another fixed-suture strabismus study, Kachko et al evaluated the efficacy of sub-Tenon's ropivacaine $(0.2 \%)$ administered under general anesthesia at the end of surgery. ${ }^{19}$ This study found no difference in median VAS on arrival in a post-anesthesia care unit or discharge. However, the ropivacaine group had lower VAS scores between 4 and 16 hours, and required less analgesia during the first 24 hours. This contrasts to our study, in which we found similar pain scores at each time interval.

The major strength of our study is that we utilized standardized methods with discrete measurements to measure the efficacy of analgesia with the VAS and the return of full ocular motility with the Lancaster red-green test, unlike other studies which relied on subjective measurements. However, our study does have several limitations. First, patients were not randomized but rather assigned by the pharmacy; however, both the anesthesiologist and the ophthalmologist were masked to which LA was utilized in the block. Second, the administration of supplemental analgesia in the postoperative period may have influenced the pain outcomes. Third, the concentration of ropivacaine may not have been adequate to obtain the desired prolonged analgesic effect.

We conclude that the 50:50 mixture of $2 \%$ lidocaine with $0.4 \%$ ropivacaine as compared to $2 \%$ lidocaine in peribulbar anesthetic blocks in adjustable-suture strabismus surgery does not produce significant improvements in pain control during the postoperative and adjustment phases. We were able to objectively demonstrate that the addition of $0.4 \%$ ropivacaine does not impair the return of full ocular motility at 6 hours, which is advantageous in adjustable-suture surgery. These outcomes suggest that, although the addition of $0.4 \%$ ropivacaine to a peribulbar block in a 50:50 mixture with $2 \%$ lidocaine does not enhance pain control, future 
studies utilizing higher concentrations of ropivacaine may be warranted.

\section{Disclosure}

The authors report no conflicts of interest in this work.

\section{References}

1. Bielschowsky A. Die neueren Aschauungen über das Wesen und Behandlung des Schielens [The new views on the nature and treatment of strabismus]. Mediz Klin Jg 1907, Beih 12. Berlin: Urban \& Schwarzenberg, 1907. German.

2. Jampolsky A. Current techniques of adjustable strabismus surgery. Am J Ophthalmol. 1979;88:406-418.

3. Wisnicki HJ, Repka MX, Guyton DL. Reoperation rate in adjustable suture surgery. J Pediatr Ophthalmol Strabismus. 1988;25(3):112-114.

4. Mireskandari K, Cotesta M, Schofield J, Kraft SP. Utility of adjustable sutures in primary strabismus surgery and reoperations. Ophthalmology 2012;119(3):629-633.

5. Brown DR, Pacheco EM, Repka MX. Recovery of extraocular muscle function after adjustable suture strabismus surgery under local anesthesia. J Pediatr Ophthalmol Strabismus. 1992;29(1):16-20.

6. McClellan KJ, Faulds D. Ropivacaine: an update of its use in regional anaesthesia. Drugs. 2000;60(5):1065-1093.

7. Lancaster WB. The red-green test. Trans Am Acad Ophthalmol Otolaryngol. 1950;54:367-368.

8. Christoff A, Guyton DL. The lancaster red-green test. Am Orthopt J. 2006;56:157-165.

9. Rosenberg PH, Heinonen E. Differential sensitivity of A and C nerve fibres to long-acting amide local anaesthetics. Br J Anaesth. 1983;55:163-167.

10. Di Donato A, Fontana C, Lancia F, Celleno D. Efficacy and comparison of $0.5 \%$ levobupivacaine with $0.75 \%$ ropivacaine for peribulbar anaesthesia in cataract surgery. Eur J Anaesthesiol. 2006;23:487-490.
11. Borazan M, Karalezli A, Oto S, Algan C, Aydin Akova Y. Comparison of a bupivacaine $0.5 \%$ and lidocaine $2 \%$ mixture with levobupivacaine $0.75 \%$ and ropivacaine $1 \%$ in peribulbar anaesthesia for cataract surgery with phacoemulsification. Acta Ophthalmol Scand. 2007;85:844-847.

12. Nicholson G, Sutton B, Hall GM. Comparison of $1 \%$ ropivacaine with $0.75 \%$ bupivacaine and $2 \%$ lidocaine for peribulbar anaesthesia. $\mathrm{Br} J$ Anaesth. 2000;84:89-91.

13. Olmez G, Cakmak SS, Caca I, Unlu MK. Intraocular pressure and quality of blockade in peribulbar anesthesia using ropivacaine or lidocaine with adrenaline: a double-blind randomized study. Tokohu J Exp Med. 2004;204(3):203-208.

14. Perello A, George J, Skelton V, Pateman J. A double-blind randomised comparison of ropivacaine $0.5 \%$, bupivacaine $0.375 \%$ - lidocaine $1 \%$ and ropivacaine $0.5 \%$ - lidocaine $1 \%$ mixtures for cataract surgery. Anaesthesia. 2000;55:1003-1007.

15. Nociti JR, Serzedo PS, Zuccolotto EB, Cagnolati CA, Nunes AM. Ropivacaine in peribulbar block: a comparative study with bupivacaine. Acta Anaesthesiol Scand. 1999;43(8):799-802.

16. Gioia L, Fanelli G, Casati A, et al. A prospective, randomized, double-blinded comparison of ropivacaine $0.5 \%, 0.75 \%$, and $1 \%$ ropivacaine for peribulbar block. $J$ Clin Anesth. 2004;16:184-188.

17. Kallio H, Puska P, Summanen P, Paloheimo M, Maunuksela EL. Retrobulbar/peribulbar block with $0.2 \%$ ropivacaine or $1 \%$ lidocaine for transscleral cyclophotocoagulation or retinal panphotocoagulation. Reg Anesth Pain Med. 1999;24(4):341-346.

18. Walters G, Stewart OG, Bradbury JA. The use of subtenon ropivacaine in managing strabismus with adjustable sutures. JAAPOS. 2001;5(2): 95-97.

19. Kachko L, Katz J, Axer-Siegel R, et al. Sub-Tenon's ropivacaine block for pain relief after primary strabismus surgery. Curr Eye Res. 2010;35(6):529-535.

20. Bodian CA, Freedman G, Hossain S, Eisenkraft JB. The Visual Analog Scale for Pain. Anesthesiology. 2001;95(6):1356-1361.
Journal of Pain Research

\section{Publish your work in this journal}

The Journal of Pain Research is an international, peer-reviewed, open access, online journal that welcomes laboratory and clinical findings in the fields of pain research and the prevention and management of pain. Original research, reviews, symposium reports, hypothesis formation and commentaries are all considered for publication.

\section{Dovepress}

The manuscript management system is completely online and includes a very quick and fair peer-review system, which is all easy to use. Visit http://www.dovepress.com/testimonials.php to read real quotes from published authors. 